\title{
MARCAS DE MORDIDA: AVALIAÇÃO DO EMPREGO DA COLA A BASE DE CIANOCRILATO EM CASO PERICIAL SIMULADO
}

\section{BITE MARKS: EVALUATION OF THE USE OF CYANOCRILATE GLUE IN A SIMULATED EXPERT CASE}

\author{
Luísa Felin Santi ${ }^{1}$, Lauren Volquind ${ }^{2}$, Mariá Bellan ${ }^{3}$, Alexandre Conde ${ }^{4}$
}

\author{
Submetido: 04/01/2021 \\ Aprovado: 21/01/2021
}

\begin{abstract}
RESUMO
Marcas de mordida são lesões que contribuem na identificação de agressores, vítimas e criminosos. Essas podem ser encontradas em alimentos em cenas de crimes. O objetivo deste estudo foi identificar se a cola a base de cianoacrilato tem empregabilidade como agente estabilizador dimensional para suporte inanimado (goma de mascar), em propósitos periciais de confronto de mordida. Foi selecionado um paciente em tratamento regular no Complexo Odontológico da FSG Centro Universitário, que foi convidado a participar do estudo através da assinatura do TCLE. Foi realizada a moldagem da arcada superior e inferior do paciente para confecção de modelo de gesso, foi solicitado, também, que mastigasse uma goma de mascar durante 5 minutos. Após, foi utilizado cola a base de cianocrilato na goma, com o objetivo de estabilização dimensional. $O$ material de moldagem empregado foi silicone de adição, tanto para os modelos das arcadas, quanto para duplicação da goma. Para a verificação de alteração dimensional, foi utilizando a Análise Métrica com compasso de ponta seca e paquímetro digital, medindo as pontas de cúspides. Para o confronto foram feitas fotos dos modelos de gesso (goma de mascar e arcadas superior e inferior) com câmera fotográfica de 12MP e sobreposição manual com folha transparente de acetado, empregando caneta para retroprojetor. Os resultados apontaram não haver variação das medidas obtidas entre os modelos de arcadas e o modelo da goma de mascar. Logo, foi possível concluir que, a utilização da cola a base de cianoacrilato tem empregabilidade como agente estabilizador dimensional em goma de mascar.
\end{abstract}

PALAVRAS-CHAVE: Odontologia Legal. Identificação Humana. Alimentos.

\begin{abstract}
Bite marks are injuries that contribute to the identification of aggressors, victims and criminals. Can be found in food at crime scenes. This study aims to identify if the cyanoacrylate based glue has employability as a dimensional stabilizing agent for inanimate support (chewing gum), in expert bite confrontation purposes. A patient under regular treatment was selected at the Complexo Odontológico da FSG Centro Universitário, who was invited to participate in the study by signing the informed consent form. The patient's upper and lower arches were molded to make a plaster model, and he was also asked to chew a chewing gum for 5 minutes and afterwards, cyanoacrylate-based glue was used on the gum for dimensional stabilization. The molding material used was the addition silicone, both for the arcade models and for gum duplication. For the verification of dimensional alteration, it was used the Metric Analysis with dry-point compass and digital pachymeter, measuring the cusps tips. For the comparison, photos of the plaster models (chewing gum and upper and lower arches) were taken with a 12MP camera and manual overlay, with transparent acetate sheet, using overhead projector pen. The results showed that there was no variation in the measurements obtained between the arcade models and the chewing gum model and it was possible to conclude that, with the use of cyanoacrylate based glue, the chewing gum did not have dimensional changes in the measured points.
\end{abstract}

KEYWORDS: Forensics Hentistry. Human Identification. Food.

\footnotetext{
1 Graduanda do curso de Graduação em Odontologia - FSG Centro Universitário - Caxias do Sul/RS ORCID: https://orcid.org/0000-0002-2278-3494

2 Graduanda do Curso de Graduação em Odontologia - FSG Centro Universitário - Caxias do Sul/RS ORCID: https://orcid.org/0000-0002-5405-3752

3 Mestre em Materiais Dentário- Professor do Curso de Graduação em Odontologia - FSG Centro Universitário Caxias do Sul/RS ORCID: https://orcid.org/0000-0002-7074-3518

4 Doutor em Materiais Dentários - Professor do Curso de Graduação em Odontologia - FSG Centro Universitário - Caxias do Sul/RS ORCID: https://orcid.org/0000-0003-0224-2313
} 


\section{RECIMA21 - REVISTA CIENTÍFICA MULTIDISCIPLINAR}

MARCAS DE MORDIDA: AVALIAÇÃO DO EMPREGO DA COLA A BASE DE CIANOCRILATO

EM CASO PERICIAL SIMULADO

Luísa Felin Santi, Lauren Volquind, Mariá Bellan, Alexandre Conde

\section{INTRODUÇÃO}

As marcas de mordida podem contribuir para identificar o agressor através da lesão causada, sendo usadas como evidência em laudos periciais, pois cada indivíduo tem características dentais que causam impressões na pele, que são passiveis de identificá-lo, sendo assim, é muito utilizado na odontologia legal nas investigações forenses para identificar o sujeito que cometeu a agressão e excluir suspeitos ${ }^{1}$.

E podem ser causadas por um ou mais dentes sozinhos ou em combinação com outras partes da boca. E são estudados na pele da vítima ou do agressor e nos alimentos que permanecem localizados na cena do crime em que são utilizadas técnicas, para registrar e analisar marcas de mordida ${ }^{2}$.

As técnicas melhoraram bastante nos últimos anos e são as técnicas clássicas de comparação, que podem ser diretas (com a comparação do modelo dos dentes do suspeito com marca de mordida ou fotografias da mesma) e indiretas (que possuem facilidades, mas podem introduzir a erros na análise, como sobreposições e traços aparentes) ${ }^{2}$.

As marcas de mordida podem ser usadas para vincular um suspeito a um crime e estabelecer uma ligação entre a pessoa mordida e o mordedor ou excluir os inocentes e para elucidar o tipo de violência e o tempo decorrido entre a sua produção e identificação avaliando se a marca foi produzida em vida ou pós-morte ${ }^{3}$.

No campo criminal, os alimentos são os objetos mais frequente nas cenas das infrações que apresentam marcas dentárias. Legalmente, como indicador de um crime, as marcas são aceitas desde 1954 pela corte dos Estados Unidos da América, onde um infrator foi detectado através das impressões de seus dentes deixadas em um pedaço de queijo. Pode-se averiguar grande número de depoimentos e esclarecimento de crimes que ocorreram através da identificação do agressor pelas marcas de mordida em algum tipo de objeto ou alimento que fora esquecido no local do ocorrido 4 .

O perito odonto-legal deve perceber características diferenciadas, como espaços com perdas de dentes, lacerações, que ocorrem de acordo com a forma dos elementos dentários com ou sem restaurações, largura e comprimento do arco (grande ou pequeno) e posicionamento dos dentes. Estes delitos são normalmente associados à violência, usando da força física na tentativa de impor sua vontade a alguém para fazer ou deixar de fazer algo 5 .

Nos alimentos, quando ocorre a mordida, os dentes superiores vão agarrar e os inferiores rasgam, fazendo o registro do limite oclusal ou de maior contorno dos elementos dentários 


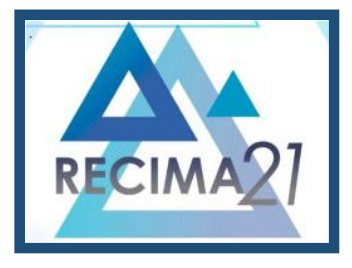

\section{RECIMA21 - REVISTA CIENTÍFICA MULTIDISCIPLINAR}

MARCAS DE MORDIDA: AVALIAÇÃO DO EMPREGO DA COLA A BASE DE CIANOCRILATO

EM CASO PERICIAL SIMULADO

Luísa Felin Santi, Lauren Volquind, Mariá Bellan, Alexandre Conde

envolvidos. Queijo, maçã, chocolate e pastilha elástica são mais frequentemente localizados nas áreas de crimes, sendo que a última tem grande eficácia de cópia da face oclusal ${ }^{6}$.

Portanto, o objetivo deste trabalho foi identificar se a cola a base de cianocrilato tem empregabilidade como agente estabilizador dimensional para alguns suportes inanimados em propósitos periciais de confronto de mordida.

\section{REFERENCIAL TEÓRICO}

Para o presente trabalho, se faz necessário a lembrança de alguns tópicos, tais como: Identificação Humana; Odontologia Legal; Marcas de Mordida; Técnicas de registro de mordida; Casos relatados.

\subsection{Odontologia}

Muitas vezes, os corpos estão carbonizados, fragmentados, macerados, mutilados ou em avançado estado de decomposição, o que dificulta ou impossibilita o reconhecimento pela inspeção visual e a identificação pelo método datiloscópico, uma vez que as polpas digitais são destruídas no processo de degeneração do corpo. Uma das maiores virtudes do método de identificação pela análise dos arcos dentais é a sua eficiência em situações adversas, pois os dentes são estruturas altamente mineralizadas, que possuem grande durabilidade, longevidade e alta resistência a condições extremas de degradação, como alterações de pressão, temperatura e umidade. $O$ método odontológico também apresenta menor tempo de trabalho quando comparado ao exame de DNA, além de excelente confiabilidade, desde que realizado com critério e minúcia, sendo, em determinadas condições, o único passível de aplicação?

\subsection{Odontologia Legal}

A odontologia Legal é uma das áreas das Ciências Forenses responsável pela investigação de fenômenos psíquicos, físicos, químicos e biológicos que podem atingir os seres humanos (vivo, morto, ossada e fragmentos).

Segundo a Lei 5081 de 24 de agosto de 1966 art. $6^{\circ}$, compete ao cirurgião dentista, proceder à perícia odonto-legal em foro civil, criminal, trabalhista e em sede administrativa e utilizar, no exercício da função de perito-odontólogo, em casos de necropsia, as vias de acesso do pescoço e da cabeça $^{10}$.

O perito odonto-legal é um cirurgião dentista especializado que realiza desenhos, esquemas, fotografias e tudo que for necessário para que o exame fique bem descrito. Dentre as áreas de competência do odontologista, é de suma importância a atuação em perícias criminais, tanatologia forense e identificação humana que são meios pelos quais o cirurgião-dentista pode auxiliar a solucionar crimes e identificar vítimas. Existem os peritos oficiais e não oficiais: os peritos oficiais 


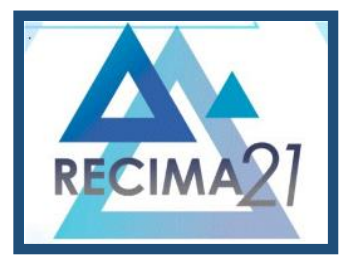

\section{RECIMA21 - REVISTA CIENTÍFICA MULTIDISCIPLINAR}

MARCAS DE MORDIDA: AVALIAÇÃO DO EMPREGO DA COLA A BASE DE CIANOCRILATO

EM CASO PERICIAL SIMULADO Luísa Felin Santi, Lauren Volquind, Mariá Bellan, Alexandre Conde

exercem a função por atribuição de cargo público (médicos legistas, peritos criminais e odontolegistas), realizam os exames de corpo de delito, fazendo exames, elaboração e assinatura dos laudos. Os peritos não oficiais são designados na falta de peritos oficiais, ou substituí-los, quando estiverem impedidos ou impossibilitados de trabalhar ${ }^{3}$.

\subsection{Identificações Humanas}

A identidade é o conjunto de características morfofisiológicas e psíquicas exclusivas de uma pessoa, sendo definida por processo objetivo, baseado em fundamentos científicos. É um dever do Estado e direito de todo cidadão ser identificado. Com isso, os princípios éticos e morais dizem que sejam utilizados todos os esforços disponíveis para localizar e identificar o maior número possível de pessoas envolvidas em uma tragédia ${ }^{7}$.

\subsection{Datiloscopia}

A datiloscopia como método de identificação humana, realizado através das impressões digitais, é um meio de prova que pode ser realizado por um perito ou papiloscopista, que são os profissionais responsáveis pela emissão do laudo técnico. É um dos ramos da papiloscopia muito utilizado no mundo todo, principalmente por ser um método simples, de baixo custo em relação a outros métodos e que dispõe de confiabilidade, já que tem o aspecto da perenidade, imutabilidade e variabilidade dos desenhos digitais que se formam na polpa dos dedos e possui grande utilidade no Processo Penal Brasileiro, por ser um meio de prova no qual se pode chegar à verdade sobre a autoria de um delito, através da análise das impressões digitais ${ }^{8}$.

\subsection{DNA}

O perfil genético tem sido considerado importante na identificação individual, pois a informação contida no DNA é determinada por uma sequência específica de bases nitrogenadas. As letras do alfabeto genético estão dispostas no DNA, que se enovela na forma de cromossomos. As evidências biológicas (manchas de sangre, sêmen, cabelo etc.) são encontradas em cenas de crimes e o DNA pode ser extraído dessas evidências e estudado por técnicas laboratoriais moleculares, permitindo a identificação do possível suspeito. Atualmente a identificação humana por DNA Forense é aceita em processos judiciais em todo o mundo, sendo possível inclusive a identificação de pessoas mortas a centenas de anos, utilizando DNA obtido de ossos ou dentes ${ }^{9}$.

\subsection{Marcas de Mordida}

As mordeduras são os vestígios, sinais, estigmas, marcas ou impressões deixadas pelos órgãos dentários humanos, alimentos, vestes ou objetos com consistência relativamente mole ou amolecida, causas por um indivíduo que pode ser agressor ou vítima e que são utilizados em casos periciais e avaliados por peritos, avaliando características incomuns na marca de mordida, como lacerações que podem ocorrer de acordo com as singularidades na forma das unidades dentárias ou 


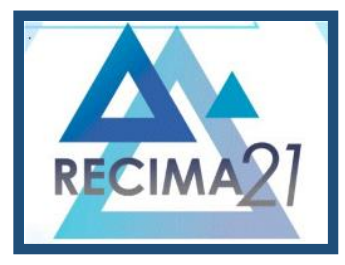

\section{RECIMA21 - REVISTA CIENTÍFICA MULTIDISCIPLINAR}

MARCAS DE MORDIDA: AVALIAÇÃO DO EMPREGO DA COLA A BASE DE CIANOCRILATO

EM CASO PERICIAL SIMULADO

Luísa Felin Santi, Lauren Volquind, Mariá Bellan, Alexandre Conde

restaurações, espaçamento entre os dentes sugestivos de perda dentária, apinhamento, mau posicionamento de dentes, largura e comprimento dos arcos dentários ${ }^{11}$.

\subsection{Técnica de Registro}

As marcas de mordida podem ser encontradas tanto em suportes animados quanto inanimados. As primeiras circunscrevem-se à pele, ora das vítimas (supérstites ou fenecidas), ora dos próprios suspeitos, enquanto as segundas abrangem uma amplíssima gama de alimentos e objetos.

\subsection{Substratos Inanimados}

Em relação aos suportes inanimados podem ser objetos ou alimentos, em que se enfatiza que, gomas de mascar, frutas e queijos, pois são os alimentos encontrados com mais frequência no local do delito, embora não discriminem as suas respectivas variedades. A goma de mascar é o alimento mais diferenciado, pois sua feição grudenta e viscosa dificulta a reprodução da morfologia dentária, em face de sua tendência de se aderir às superfícies mastigatórias e se distorcer. Outro problema também é a justaposição de mordeduras repetidas e sua conformação específica, e delineia-se pela pressão das cúspides de caninos, pré-molares e molares que se assemelha à deixada pelos homólogos de gatos e cães, dando lugar, assim, a conclusões inexatas plausíveis. Os substratos inanimados perecíveis são sensíveis às condições ambientais (temperatura e umidade), e podem ser passíveis de desidratação e reações químicas que alteram a sua coloração natural e a aparência peculiar das mordeduras ${ }^{11}$.

\subsection{Substratos Animados}

Quando a marca de mordida está presente na pele de um indivíduo, ela pode estar presente tanto no agressor quanto na vítima e se apresenta de duas formas: quando é produzida de forma devagar apresenta área equimótica no centro da lesão procedente da sucção ou da pressão da língua, sendo mais comum em ataques sexuais. A outra forma é a marca deixada pelos dentes e é mais frequente em situações de ataque e defesa, com maiores ocorrências em casos de violência infantil e homicídios ${ }^{12}$.

\subsection{Técnica de Confronto}

As técnicas de confronto que podem ser utilizadas são comparações de marcas de mordida, podem ser realizada através dos métodos da análise métrica ou da superposição de imagens. $O$ primeiro consiste na mensuração de particularidades dentárias como o comprimento, largura e a profundidade dente específico; o tamanho e a forma, espaço entre as marcas dos dentes, distância intercanina; ausência de dentes; dentes mal posicionados e outros. No segundo método, o principal instrumento é a sobreposição das imagens entre a mordida e o arco dentário suspeito, verificando os pontos que coincidem e os que divergem. A sobreposição pode ser feita de forma manual ou através 


\section{RECIMA21 - REVISTA CIENTÍFICA MULTIDISCIPLINAR}

MARCAS DE MORDIDA: AVALIAÇÃO DO EMPREGO DA COLA A BASE DE CIANOCRILATO

EM CASO PERICIAL SIMULADO Luísa Felin Santi, Lauren Volquind, Mariá Bellan, Alexandre Conde

de imagens digitais. No modo manual é utilizada uma folha de acetato transparente, posicionada sobre o modelo de gesso do arco do suspeito, possibilitando copiar as superfícies incisais e posteriormente sobrepostas às impressões dentárias (mordida). As técnicas digitais são feitas através das imagens escaneadas ou fotografias digitais, podendo ser manipuladas através do programa de computadores ${ }^{12}$.

\subsection{Casos relatados}

O autor Sperber $^{13}$ (1978) descreve o primeiro caso da literatura em que uma goma de mascar provou ser parte essencial da evidência de um crime, conduzindo um homicida a condenação. Alguns dias antes do Natal de 1976, na cidade de San Diego, Califórnia (EUA), foi encontrado um cadáver e no local do crime os detetives identificaram uma goma de mascar, que foi armazenada sob refrigeração. Duas mulheres suspeitas foram presas, sendo que uma delas foi identificada através de impressões digitais presentes no local do crime, e a outra, apesar da ausência de provas, continuou sob prisão devido a fortes indícios de sua participação no crime. A goma de mascar apresentava marcas características das superfícies linguais de incisivos superiores. Foi feita a reprodução do suporte com silicone e, posteriormente, o confronto com os modelos de gesso da vítima e dos suspeitos. Durante o estudo pericial da goma, observou-se uma depressão na face lingual de um dos incisivos que coincidia com a cavidade aberta para fins endodônticos do dente da segunda suspeita. À distância inter-dentária também serviu como mais um ponto coincidente. Após a análise de evidência física, foi feita a determinação do tipo sanguíneo da pessoa que mascou a goma com a saliva, que também se mostrou compatível com o da suspeita, sendo mais uma prova da ligação desta com o crime. Baseados nestes achados, a Corte de San Diego sentenciou as suspeitas.

Nos trabalhos científicos de Galvão et al. ${ }^{14}$ (1999) e Marques ${ }^{15}$ (2004), os autores identificaram mordidas em maçãs, barras de chocolate e gomas de mascar, entre os integrantes da amostra da pesquisa. Foram realizadas fotografias em vista panorâmica e em close, com e sem flash, em cores e preto e branco e no presente estudo, foram utilizadas fotografias de uma câmera de celular, em cores, algumas imagens com e sem flash. Os alimentos forma mantidos sob refrigeração a $4^{\circ} \mathrm{C}$ e a técnica de registro foi realizada com silicone de condensação, pela técnica de dupla impressão e os moldes foram vazados com gesso tipo IV. A goma de mascar foi vazada separadamente, em cada uma das suas superfícies, com silicone leve, utilizando uma seringa descartável, para a construção dos positivos, os quais foram reforçados com silicone pesado, mediando uma fase de refrigeração antes de proceder à retirada de cada um deles, assim como o presente estudo, porém, o alimento não foi mantido em refrigeração, pois se caracteriza como um caso pericial simulado e foi utilizado o silicone de adição, que possui ponteiras misturadoras que garantem uma homogeneidade no material fluido, assim como facilidade de manipulação e também foi utilizado o gesso tipo IV. A técnica de confronto utilizada foi a análise métrica, mediante compasso 


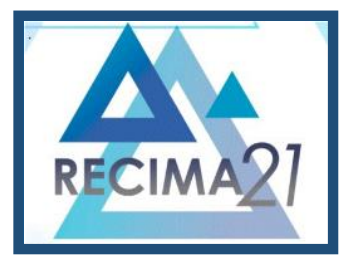

\section{RECIMA21 - REVISTA CIENTÍFICA MULTIDISCIPLINAR}

MARCAS DE MORDIDA: AVALIAÇÃO DO EMPREGO DA COLA A BASE DE CIANOCRILATO

EM CASO PERICIAL SIMULADO

Luísa Felin Santi, Lauren Volquind, Mariá Bellan, Alexandre Conde

de ponta seca, de todos esses materiais de estudo e com a goma de mascar foi possível executar a técnica de identificação positiva, assim como o presente estudo.

A equipe de Caldas et al. ${ }^{16}$ (2000), composta por vários peritos em diversas áreas, solicitou um dentista, percebendo a importância do alimento coletado como prova. Foi encontrado um bombom, em que foi realizado moldagens com alginato e silicone de condensação na tentativa de se reproduzir os dentes do autor da mordida. Foi vazado gesso no molde em negativo e obtido o modelo em positivo dos dentes, especificamente anteriores superiores e inferiores. E no suspeito foi moldado os dentes anteriores superiores com alginato e obtido modelos em positivo em gesso e em resina acrílica, segundo o autor, com finalidade de facilitar o estudo e não desgastar durante a manipulação. Para o confronto foi utilizada comparação direta, em que o modelo dos dentes do suspeito foi colocado sobre o modelo das impressões dentais do bombom e estes tiveram encaixe perfeito e análise métrica, com paquímetro para mensurar a largura mésio-distal das incisais dos dentes anteriores superiores do modelo do bombom e do modelo do suspeito e comparamos os valores das medidas obtidas.

Karazalus, Palmbach e Lee $^{17}$ (2001) descreveram a utilização do programa Lucis para o melhoramento da imagem fotográfica digitalizadas de dois casos de homicídios em que as únicas evidências para estudo pericial eram fotográficas de má qualidade e que com o uso do software, foi possível o melhoramento da imagem que aumentou a visualização da lesão e facilitou a investigação.

\section{MÉTODO E TÉCNICAS DE PESQUISA}

\section{a. Problema da pesquisa}

A problemática do estudo se dá através da duplicação dos resquícios de prova. E como já é dito por Daruge et al. (2017), a goma de mascar é um alimento diferenciado, pois sua feição grudenta e viscosa dificulta a reprodução da morfologia dentária, em face de sua tendência de se aderir às superfícies mastigatórias e se distorcer, além da justaposição de mordeduras repetidas e sua conformação específica, assim foi observado, pois apesar de estar estabilizada, ela sofre deformações na mastigação e assim não teve a impressão exata dos elementos.

\section{b. Tipo de pesquisa}

O presente trabalho foi aprovado pelo Comitê de ética em pesquisa (CEP), sobre o parecer número 4.178.140 / CAAE: 34264720.3.0000.5668 (Anexo I), tratando-se de um relato de caso quanti-qualitativo, experimental, transversal, descritivo, laboratorial.

Foi autorizado pela coordenação do curso de odontologia através da Carta de Anuência, submetido ao Comitê de Ética em Pesquisa da FSG Centro Universitário e somente teve início após a sua aprovação. O pesquisado escolhido concordou em participar da pesquisa, assinando o Termo 


\section{RECIMA21 - REVISTA CIENTÍFICA MULTIDISCIPLINAR}

MARCAS DE MORDIDA: AVALIAÇÃO DO EMPREGO DA COLA A BASE DE CIANOCRILATO

EM CASO PERICIAL SIMULADO Luísa Felin Santi, Lauren Volquind, Mariá Bellan, Alexandre Conde

de Consentimento Livre e Esclarecido em duas vias, uma para o pesquisado e a outra para o pesquisador, assinou o Termo de Consentimento para Uso de Imagens Relacionadas à Pesquisa Científica e o(s) pesquisador (es) da pesquisa assinaram o Termo de Confidencialidade.

\section{c. Justificativa}

O presente estudo se justifica e vem ao encontro do assunto, trazendo a possibilidade de trazer informações que deem mais segurança ao perito no uso da cola de cianocrilato e, consequentemente, a decisão pelo seu emprego (ou não) embasado em artigo com metodologia científica embasada, levando em consideração que a cola a base de cianocrilato é um material de fácil disponibilidade que pode ser empregado em situações em que é necessário manter a estabilidade dimensional de alimentos inanimados, eventualmente encontrados em cenas de crimes.

\section{d. Metodologia}

A abordagem clínica consistiu em duas consultas clínicas:

Na primeira consulta, a pesquisadora realizou a paramentação adequada e fez o preparo do ambiente clínico. Após isso, com a chegada do paciente, foi realizada a moldagem com moldeiras metálicas (Moldeira de aço inox - Tecnodent - Indaiatuba - Brasil) número S-2 e I-1, e utilizado o material elastômero irreversível na moldeira (silicone de adição pesada e fluida) (Kit Silicone de Adição Panasil Putty Soft 400ml + Panasil Light - KettenbachGmbH\&Co, KG - Eschengurg Alemanha), realizado os alívios com lâmina de bisturi número 15 (Lâmina de bisturi descartável n 15 - MAXICOR - Pinhais - Brasil) e moldagem com o elastômero irreversível fluido (Kit Silicone de Adição Panasil Putty Soft $400 \mathrm{ml}+$ Panasil Light- KettenbachGmbH\&Co, KG - Eschengurg Alemanha) com auxílio da pistola (Dispensador (Pistola) DFL - 3M - Minnesota - EUA) e ponteira misturadora (ponteira misturadora - KettenbachGmbH\&Co, KG - Eschengurg - Alemanha).

Depois do procedimento de moldagem, foi feita a desinfecção do molde com hipoclorito de sódio (Hipoclorito de sódio 1\% - PROLINK Industria Química LTDA. - São Paulo - Brasil) e realizado o vertimento de gesso (tipo IV) (Gesso Pedra Especial Durone Marfim IV - DENTSPLY SIRONA São Paulo - Brasil). Logo em seguida, o pesquisado foi dispensado com marcação da segunda consulta para data futura.

Após duas horas, os modelos de gesso foram removidos dos moldes e foi dado acabamento em desgastadora de gesso (Desgastadora de gesso, VRC Equipamentos, São Paulo, Brasil).

A segunda consulta consistiu na entrega de uma goma de mascar (Chiclete de Bola Buzzy RICLAN S.A - Rio Claro - Brasil) ao paciente para mastigar por 5 minutos. Após o tempo de mastigação, foi descartada a goma de mascar em copo plástico (Copo Plástico Descartável Copobras - São Ludgero - Brasil).

No laboratório de Prótese da FSG Centro Universitário, foi utilizado um fio dental (Fita dental - Sanifill - Rio de Janeiro - Brasil) enrolado em cima do seu próprio eixo e dado um nó na ponta, 


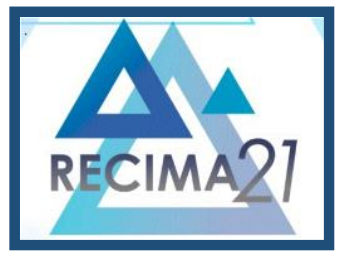

\section{RECIMA21 - REVISTA CIENTÍFICA MULTIDISCIPLINAR}

MARCAS DE MORDIDA: AVALIAÇÃO DO EMPREGO DA COLA A BASE DE CIANOCRILATO

EM CASO PERICIAL SIMULADO Luísa Felin Santi, Lauren Volquind, Mariá Bellan, Alexandre Conde

cortado com tesoura íris (Tesoura Íris reta - GOLGRAN - São Caetano do Sul - Brasil) para dar formato de delicado pincel com cerdas.

Posteriormente, foi aplicado a cola a base de cianocrilato (Cola TeckBond-Saint-Gobain São Paulo - Brasil) nas cerdas para encostar na parte desprovida de registro dentário da goma de mascar, que estava dentro do copo plástico, para poder retirar a goma de mascar do interior do mesmo sem deformá-lo.

Então, aplicou-se fina camada de cola a base de cianocrilato (Cola TeckBond-Saint-Gobain - São Paulo - Brasil) na goma de mascar com o propósito de estabilizá-la dimensionalmente, aplicado jato de ar para a cola espalhar-se por toda a peça e então esperado que a cola polimerize quimicamente.

Finalizando esse processo, foi aplicado o material de moldagem elastomérico fluído Silicone de adição (Kit Silicone de Adição Panasil Putty Soft 400ml + Panasil Light- KettenbachGmbH\&Co, KG - Eschengurg - Alemanha) por toda a peça de goma de mascar com auxílio da pistola (Dispensador (Pistola) DFL - 3M - Minnesota - EUA) e ponteira misturadora (ponteira misturadora KettenbachGmbH\&Co, KG - Eschengurg - Alemanha) com o silicone de adição fluida (Panasil LightKettenbach GmbH\&Co, KG - Eschengurg - Alemanha) e aguardado a vulcanização do material.

A moldagem foi separada manualmente, para ser realizada a duplicação da goma de mascar. Após foi aplicado silicone de adição de outra cor (roxa) (Silicone de adição pasta fluida Express XT DFL - 3M - Minnesota - EUA) para fazer uma cópia positiva, que duplica goma de mascar, para viabilizar a deposição de gesso.

Então as duas metades foram unidas, para a realização da duplicação da goma de mascar e realizadas marcações com a caneta para retroprojetor para melhor localizar o lado superior e inferior. Em seguida, manipulado o gesso tipo IV (Gesso Pedra Especial Durone Marfim IV - DENTSPLY SIRONA - São Paulo - Brasil) utilizando as medidas indicadas pelo fabricante, foi realizada a manipulação e incorporação do pó de gesso à água e vertido no molde do alimento moldado (fig. 1).

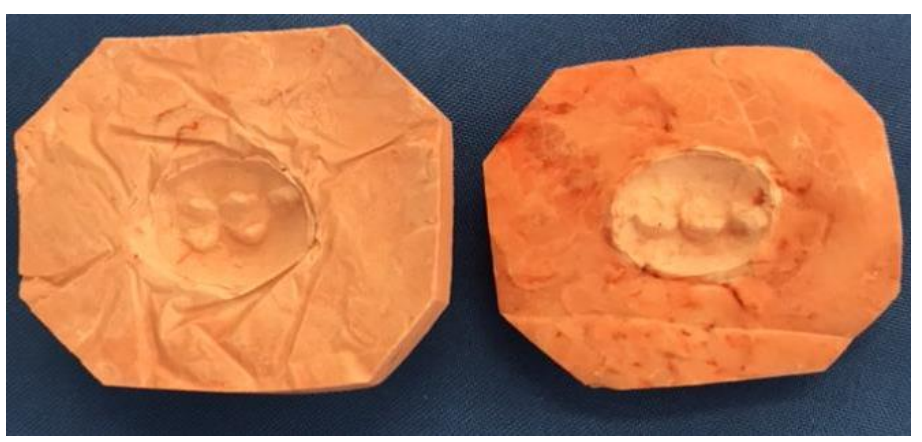

Figura 1: Modelos de gesso da duplicação da goma de mascar com gesso tipo IV. A direita, modelo de gesso das faces oclusais superior da goma de mascar e a esquerda modelo de gesso das faces oclusais inferior da goma de mascar.

Foram analisados os modelos de gesso superior e inferior, tanto da goma de mascar como das arcadas do paciente utilizando a análise métrica, e comparação indireta, conforme Daruge et 


\section{RECIMA21 - REVISTA CIENTÍFICA MULTIDISCIPLINAR}

MARCAS DE MORDIDA: AVALIAÇÃO DO EMPREGO DA COLA A BASE DE CIANOCRILATO

EM CASO PERICIAL SIMULADO Luísa Felin Santi, Lauren Volquind, Mariá Bellan, Alexandre Conde

al. ${ }^{11}$ (2017), mediante compasso de ponta seca (Compasso de Ponta Seca - ICE - São Paulo Brasil).

As distâncias intercuspídicas foram obtidas com um paquímetro da marca Mitutuyo (Paquímetro Digital em Fibra de Carbono - Mitutoyo - São Paulo - Brasil), cada um dos dentes presentes no modelo de gesso e na duplicação em gesso da goma de mascar.

Foi colocado as pontas secas do compasso nas pontas das cúspides do elemento 14 do modelo de gesso da arcada do pesquisado com subsequente obtenção da distância intercuspídica empregando o paquímetro digital Mitutoyo através da leitura de seu display digital. Mesmo procedimento foi feito nas pontas das cúspides do modelo de gesso da goma de mascar do dente 14 .

Foi colocado as pontas secas do compasso nas pontas das cúspides do elemento 15 do modelo de gesso da arcada do pesquisado com subsequente obtenção da distância intercuspídica empregando o paquímetro digital Mitutoyo através da leitura de seu display digital. Mesmo procedimento foi feito nas pontas das cúspides do modelo de gesso da goma de mascar do dente 15.

Foi colocado as pontas secas do compasso, uma na ponta da cúspide palatina do elemento 14 e a outra na ponta de cúspide palatina do elemento 15 do modelo de gesso da arcada do pesquisado com subsequente obtenção da distância intercuspídica empregando o paquímetro digital Mitutoyo através da leitura de seu display digital. Mesmo procedimento foi feito nas pontas das cúspides do modelo de gesso da goma de mascar dos dentes 14 e 15 . O mesmo procedimento ocorreu na cúspide vestibular do elemento 14 e cúspide vestibular do elemento 15.

Foi colocado as pontas secas do compasso, uma na ponta da cúspide do elemento 43 e a outra na ponta de cúspide vestibular do elemento 44 do modelo de gesso da arcada do pesquisado com subsequente obtenção da distância intercuspídica empregando o paquímetro digital Mitutoyo através da leitura de seu display digital. Mesmo procedimento foi feito nas pontas das cúspides do modelo de gesso da goma de mascar dos dentes 43 e 44 .

Foi colocado as pontas secas do compasso, uma na ponta da cúspide vestibular do elemento 44 e a outra na ponta de cúspide vestibular do elemento 45 do modelo de gesso da arcada do pesquisado com subsequente obtenção da distância intercuspídica empregando o paquímetro digital Mitutoyo através da leitura de seu display digital. Mesmo procedimento foi feito nas pontas das cúspides do modelo de gesso da goma de mascar dos dentes 44 e 45.

Foi colocado as pontas secas do compasso, uma na ponta da cúspide do elemento 43 e a outra na ponta de cúspide vestibular do elemento 45 do modelo de gesso da arcada do pesquisado com subsequente obtenção da distância intercuspídica empregando o paquímetro digital Mitutoyo através da leitura de seu display digital. Mesmo procedimento foi feito nas pontas das cúspides do modelo de gesso da goma de mascar dos dentes 43 e 45 .

O confronto por sobreposição manual consistiu em fazer fotos do modelo de gesso da arcada com o modelo de gesso da goma de mascar empregando um Smartphone, com câmera fotográfica de 12MP (1334 x 750 pixels) da marca Apple, modelo Iphone 7 (Iphone 7 - Apple Inc. - Cupertino - 


\section{RECIMA21 - REVISTA CIENTÍFICA MULTIDISCIPLINAR}

MARCAS DE MORDIDA: AVALIAÇÃO DO EMPREGO DA COLA A BASE DE CIANOCRILATO

EM CASO PERICIAL SIMULADO Luísa Felin Santi, Lauren Volquind, Mariá Bellan, Alexandre Conde

EUA) fazendo uma única foto para as faces oclusais superiores de ambos os modelos de gesso. $O$ mesmo foi repetido para as faces oclusais inferiores de ambos os modelos de gesso. $E$ anotação dos pontos de coincidência.

Em seguida, foi utilizado folha transparente de acetato (Folha transparente de Acetato Cristal 0,3 mm - BIO-ART - São Paulo - Brasil) a qual foi colocada sobre a foto do modelo de gesso da goma de mascar e marcada as pontas das cúspides com caneta a base de álcool (Caneta para Retroprojetor preta $2 \mathrm{~mm}$ - FABER CASTELL - Stein - Alemanha). Logo em seguida, a folha de acetato foi colocada sobre a foto do modelo de gesso, posicionando as pontas das cúspides já identificadas. Neste momento, foi riscado com a caneta a base de álcool o desenho da face oclusal. Assim, a folha de acetato estava pronta para poder fazer a fotografia do confronto por sobreposição manual.

\section{RESULTADOS E DISCUSSÕES}

Os resultados analisado/s através da mensuração das distâncias intercuspídicas estabelecendo como referencial a ponta da cúspide nos modelos de gesso da arcada superior e inferior foram estes descritos na tabela 1 :

Tabela 1: Mensuração das distâncias intercuspídicas dos modelos de gesso das arcadas.

\begin{tabular}{|c|c|c|}
\hline $\begin{array}{c}\text { Mensuração das } \\
\text { distâncias intercuspídicas } \\
\text { dos modelos de gesso } \\
\text { das arcadas }\end{array}$ & Localização & Valor em mm \\
\hline 14 & Cúspide vestibular até cúspide palatina & \\
\hline 15 & Cúspide vestibular até cúspide palatina & \\
\hline 14 e 15 & $\begin{array}{l}\text { Cúspide palatina do Elemento } 14 \text { até } \\
\text { cúspide palatina do Elemento } 15\end{array}$ & \\
\hline 14 e 15 & $\begin{array}{l}\text { Cúspide vestibular do Elemento } 14 \text { até } \\
\text { cúspide vestibular do Elemento } 15\end{array}$ & \\
\hline 14 e 15 & Cúspide palatina do Elemento 14 até & \\
\hline
\end{tabular}




\section{RECIMA21 - REVISTA CIENTÍFICA MULTIDISCIPLINAR}

MARCAS DE MORDIDA: AVALIAÇÃO DO EMPREGO DA COLA A BASE DE CIANOCRILATO

EM CASO PERICIAL SIMULADO Luísa Felin Santi, Lauren Volquind, Mariá Bellan, Alexandre Conde

\begin{tabular}{ll}
\hline 14 e 15 & cúspide vestibular do Elemento 15 \\
& $\begin{array}{l}\text { Cúspide vestibular do Elemento } 14 \text { até } \\
\text { cúspide palatina do Elemento } 15\end{array}$ \\
43 e 44 & Cúspide vestibular do Elemento 43 até \\
& cúspide vestibular do Elemento 44 \\
& Cúspide vestibular do Elemento 44 até \\
& cúspide vestibular do Elemento 45 \\
43 e 45 & Cúspide vestibular do Elemento 43 até \\
& cúspide vestibular do Elemento 45
\end{tabular}

Os resultados analisados através da mensuração das distâncias intercuspídicas estabelecendo como referencial a ponta da cúspide nos modelos de gesso da duplicação da goma de mascar foram estes descritos na tabela 2.

Tabela 2: Mensuração das distâncias intercuspídicas dos modelos de gesso da Goma de mascar.

$\begin{array}{ll}\begin{array}{l}\text { Mensuração das } \\ \text { distâncias intercuspídicas } \\ \text { dos modelos de gesso da } \\ \text { Goma de mascar. }\end{array} & \text { Cúspide vestibular até cúspide palatina } \\ 14 & \text { Cúspide vestibular até cúspide palatina } \\ 15 & \text { Cúspide palatina do Elemento } 14 \text { até } \\ & \text { cúspide palatina do Elemento } 15 \\ 14 \text { e } 15 & \begin{array}{l}\text { Cúspide vestibular do Elemento } 14 \text { até } \\ \text { cúspide vestibular do Elemento } 15\end{array} \\ 14 \text { e } 15 & \begin{array}{l}\text { Cúspide palatina do Elemento } 14 \text { até } \\ \text { cúspide vestibular do Elemento } 15\end{array}\end{array}$




\section{RECIMA21 - REVISTA CIENTÍFICA MULTIDISCIPLINAR}

MARCAS DE MORDIDA: AVALIAÇÃO DO EMPREGO DA COLA A BASE DE CIANOCRILATO

EM CASO PERICIAL SIMULADO Luísa Felin Santi, Lauren Volquind, Mariá Bellan, Alexandre Conde

14 e 15

Cúspide vestibular do Elemento 14 até cúspide palatina do Elemento 15

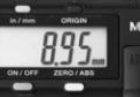

43 e 44

Cúspide vestibular do Elemento 43 até

cúspide vestibular do Elemento 44

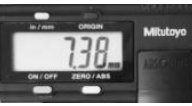

44 e 45

Cúspide vestibular do Elemento 44 até

cúspide vestibular do Elemento 45

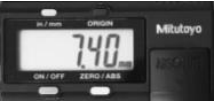

43 e 45

Cúspide vestibular do Elemento 43 até cúspide vestibular do Elemento 45

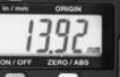

Com os resultados observados nas tabelas 1 e 2, foi possível identificar que ocorreu manutenção de distâncias intercuspídicas dos elementos dentários na comparação entre os modelos da arcada dentária com o modelo de gesso da goma de mascar, devido aos valores nas tabelas serem equivalentes. Apenas foi possível analisar as mensurações intercuspídicas de ponta de cúspide, devido à deformação de outras estruturas anatômicas dos elementos dentários, tais como vertentes e arestas. As pontas de cúspides foram facilmente marcas nas mordidas por serem mais proeminentes.

Também foi visto que, após a realização das demarcações na folha transparente de acetato e comparação das imagens do modelo de gesso do paciente e do modelo da goma de mascar as pontas das cúspides coincidiram, mas o formato dos dentes não coincidiram necessariamente na comparação dos modelos, mostrando assim uma leve deformação da goma de mascar, mas que é compreendida pelo fato da goma de mascar não ser um material de moldagem.

E assim como o artigo, o trabalho de Sperber ${ }^{13}$ (1978) também utilizou o substrato inanimado goma de mascar, entretanto, Galvão et al. ${ }^{14}$ (1999) e Marques ${ }^{15}$ (2004), além da goma de mascar, usou também maças e barras de chocolate. Caldas et al. ${ }^{16}$ (2000) não utilizou a goma de mascar, mas, o emprego de um bombom

Galvão et al..$^{14}$ (1999) usou como agente estabilizador dimensional o processo de manter o alimento sob refrigeração a $4^{\circ} \mathrm{C}$. O presente estudo empregou outro método, o emprego da cola a base de cianocrilato ${ }^{14}$.

Empregou silicone de adição, mesmo material do trabalho de Sperber ${ }^{13}$ (1978). No entanto, nos trabalhos de Galvão et al..$^{14}(1999)$, Marques ${ }^{15}$ (2004) e Caldas et al. ${ }^{16}$ (2000) foi empregado o silicone de condensação, diferentemente do presente trabalho.

O artigo reproduziu o substrato inanimado com gesso tipo IV, sendo o mesmo material empregado por Galvão et al..$^{14}$ (1999) e Marques $^{15}$ (2004). 


\section{RECIMA21 - REVISTA CIENTÍFICA MULTIDISCIPLINAR}

MARCAS DE MORDIDA: AVALIAÇÃO DO EMPREGO DA COLA A BASE DE CIANOCRILATO

EM CASO PERICIAL SIMULADO Luísa Felin Santi, Lauren Volquind, Mariá Bellan, Alexandre Conde

Utilizou fotos do modelo de gesso da arcada superior/inferior e do substrato inanimado com posterior desenho para confronto em folha transparente de acetato. Diferentemente do trabalho de Karazalus e Palmbach e Lee ${ }^{17}$ (2001) que empregaram o software Lucis. No entanto, Cameron e $\mathrm{Sims}^{18}$ (1973) usou a mesma técnica de confronto com folha transparente de acetato, como o presente trabalho, obtendo resultados de identificação positiva ${ }^{17,18}$.

Assim como o presente estudo, o trabalho de Sperber ${ }^{13}$ (1978), Caldas et al. (2000) Galvão et al. ${ }^{14}$ (1999) e Marques ${ }^{15}$ (2004) também utilizaram a técnica de confronto com a Análise métrica. Estes autores realizaram mediante compasso de ponta seca. Já Caldas et al. ${ }^{16}$ (2000) realizou mediante paquímetro digital, e o presente trabalho utilizou ambos, compasso de ponta seca e comprovação com paquímetro digital.

Galvão et al. ${ }^{14}$ (1999) e Marques ${ }^{15}$ (2004), assim como no atual trabalho, utilizam fotografias como recurso de análise. Ambos realizaram fotografias em vista panorâmica e em close, com e sem flash, em cores e preto e branco. Já no presente estudo, foram utilizadas fotografias de uma câmera de celular em close, com e sem flash, apenas em cores.

\section{CONCLUSÃO}

No presente estudo foi possível concluir que, com a utilização da cola a base de cianocrilato, a goma de mascar não teve alterações dimensionais nos pontos aferidos, devido ao fato de que as mensurações realizadas não estabeleceram diferenças numéricas entre o modelo de gesso da arcada do paciente e o modelo de gesso da goma de mascar.

\section{REFERÊNCIAS}

1. Baldissera AA, Chagas K, Conde A, Musse JO, Barros BAC, Fernandes MM. Verificação do tempo de percepção da unicidade em marcas de mordida e sua aplicação forense: estudo piloto, RBOL. 2019; 6(3):15-25.

2. González MEL, Sanchez JA, López LL. Marcas de mordida: últimas técnicas de análisis. REML. 2006; 1:47-53.

3. Coutinho CGV, Ferreira CA, Queiroz LR, Gomes LO, Silva UA. O papel do odontolegista nas perícias criminais. RFO - UPF. 2013; 18(2).

4. Nascimento MM, Sarmento VA, Beal VE, Galvão LCC, Marques JAM. Identificação de indivíduos por meio das marcas de mordida em alimentos utilizando a engenharia reversa e a prototipagem rápida: caso simulado. Arquivos em Odontologia. 2016; 48(3):134-141.

5. Marques JAM. Prevalência de lesões causadas por mordidas humanas e desenvolvimento de técnica para análise de mordidas na pele em investigações criminais. [tese de Doutorado]. Araçatuba: Faculdade de Odontologia, Universidade Estadual Paulista; 2007.

6. Madruga C. Análise Estereoscópica de Marcas de Mordida Mestrado Integrado em Medicina. [Dissertação em Medicina Dentária]. Coimbra: Faculdade de Medicina, Universidade de Coimbra; 2012. 


\section{RECIMA21 - REVISTA CIENTÍFICA MULTIDISCIPLINAR}

MARCAS DE MORDIDA: AVALIAÇÃO DO EMPREGO DA COLA A BASE DE CIANOCRILATO

EM CASO PERICIAL SIMULADO Luísa Felin Santi, Lauren Volquind, Mariá Bellan, Alexandre Conde

7. Araújo LGA, Biancalana RC, Silveira ASA, Paranhos LR, Machado CE, Silva RHA. Identificação humana de vítimas de desastres em massa: a importância e o papel da Odontologia Legal. RFO- UPF. 2014; 18(2).

8. Dolinsky LC, Pereira LMCV. DNA forense. Saúde \& Amb. 2007; 2(2):11-22.

9. Luiz VB, Luiz EAM. A (ir)refutabilidade da prova pericial datiloscópica no processo penal. [Trabalho de Conclusão de Curso de Graduação em Ciências Jurídicas]. Taubaté- SP: UNITAU; 2019.

10. Conselho Federal de Odontologia (CFO). Lei 5081 - Regula o exercício da profissão odontológica [acesso em 18/12/2020]. Disponível em: http://www.cfo.org.br/download/pdf/lei5081.pdf.

11. Daruge E, Daruge J E, Franccesquini J L. Tratado de Odontologia legal e Deontologia, Guanabara Kroogan; 2017; p. 588-607.

12. Amorim HPL, Melo BMS, Musse JO, Silva MLCA, Costa MCO, Marques JAM. Levantamento de marcas de mordidas humanas em vítimas de violência periciadas no Instituto Médico Legal de Feira de Santana-BA, entre 2007 e 2014. Arquivos Em Odontologia. 2016; 52(3):165-174.

13. Sperber ND. Valuable evidence in a recent homicide investigation. F.B.I Law Enforcement Bulletin 1978; 47:28-31.

14. Galvão LCC, Barreto CR, Soares GIC, Aguiar JF, Bastos LCM, Santos MAP et al. Identificação de mordida humana: relato de um caso simulado [Trabalho acadêmico]. Salvador: Faculdade de Odontologia, Universidade Federal da Bahia - FOUFBA; 1999.

15. Marques JAM. Metodologias de identificação de marcas de mordidas de Odontologia. [Dissertação Mestrado em Odontologia Legal e Deontologia]. São Paulo: Universidade de São Paulo; 2004.

16. Caldas JCFG, Paschini RC, Belmonte LN, Spadácio C, Daruge E. Elucidação de um crime através da marca de mordida: relato de um caso. Brasília. LAOFMEL. 2000. [acesso em 19 dez. 2020]. Disponível em: http://www.ibemol.com.br/forense2000/058.asp

17. Karazalus CP, Palmbach TT, Lee HC. Digital enhancement of sub-quality bite Mark photographs. J forensic Sci. 2001; 46(4):954-8

18. Cameron JM, Sims BG. Forensic dentistry. Edinburgh: Churchill Livingstrone; 1973. p. 157. 